\title{
Symbiotic Bacterial Flora Changes in Response to Low Temperature in Reticulitermes speratus KMT001 ${ }^{1}$
}

\author{
Dongmin $\mathrm{Lee}^{2} \cdot$ Yeong-Suk $\mathrm{Kim}^{2} \cdot$ Young-Kyoon $\mathrm{Kim}^{2} \cdot$ Tae-Jong Kim $\mathbb{D}^{2, \dagger}$
}

\begin{abstract}
Lower termites require symbiotic microbes in their gut. The microbial communities in the termites must adapt to the termite temperature. Reticulitermes speratus KMT001 from Bukhan Mountain in Seoul may require a special symbiotic microorganisms for growth in low temperature Korean habitat. A metagenomics analysis showed a dramatic change in the symbiotic bacterial flora in the gut of $R$. speratus KMT001 in response to low temperatures of $4^{\circ} \mathrm{C}$ or $10^{\circ} \mathrm{C}$. Elusimicrobia, which are endosymbionts of flagellate protists, is the dominant phylum in the termite gut at $\geq 15^{\circ} \mathrm{C}$ but its population decreased drastically at low temperature. Four representative bacterial strains isolated from $R$. speratus KMT001 in a previous study produced maximum $\beta$-glucosidase levels within the temperature range of $10^{\circ} \mathrm{C}-30^{\circ} \mathrm{C}$. Elizabethkingia sp. BM10 produced $\beta$-glucosidase specifically at $10^{\circ} \mathrm{C}$. This strain supported the existence of symbiotic bacteria for the low temperature habitat of the termite. This identified bacterium will be a resource for studying low temperature adaptation of termites, studying the gene expression at low temperatures, and developing an industrial cellulase at low temperature.
\end{abstract}

Keywords: symbiotic bacteria, Reticulitermes speratus, low temperature, Elizabethkingia

\section{INTRODUCTION}

Termites damage wood structures and cause large economic losses annually (Ghaly and Edwards, 2011). Wood invaded by termites loses its structural integrity without any apparent change but the damage is usually irreversible (Peterson et al., 2006). Termites that have invaded wood cannot be eliminated without removing the infected wood. The best way to control termites is preventing invasion. Therefore, understanding the natural habitat and survival strategy of termites is critical to control termite damage (Kim and Chung, 2017; Mun and Nicholas, 2017).

Termites inhabit all continents of the world except Antarctica (Evans et al., 2013). It is quite interesting how termites can inhabit a variety of regions from tropical rainforests to frozen soil. Reticulitermes speratus is a termite species found in Korea (Cho et al., 2010b). It has been suggested that termites originally landed on the southern region of the Korean peninsula from Japan and migrated north (Park et al., 2006; Kim et al., 2012). Termites are currently found on Bukhan

\footnotetext{
${ }^{1}$ Date Received July 10, 2018, Date Accepted November 12, 2018

2 Department of Forest Products and Biotechnology, College of Science and Technology, Kookmin University, 77 Jeongneung-ro, Seongbuk-gu, Seoul 02707, Republic of Korea

† Corresponding author: Tae-Jong Kim (e-mail: bigbell@kookmin.ac.kr, ORCID: 0000-0002-7483-0432)
} 
Mountain in Seoul, which is in the northern part of South Korea. Mean temperature in Korea during winter is close to $2^{\circ} \mathrm{C}$ (Jung et al., 2002), but termites survive and thrive the following spring.

Lower termites are considered as less evolved termites. Six out of seven termite families are lower termites. They obtain nutrients and energy mainly by digesting wood but they require support from symbiotic microbes in their gut (Brune and Ohkuma, 2011). These symbiotic microbes include protozoa (Cleveland, 1923), bacteria (Brune, 2014), and archaea (Shi et al., 2015). All symbiotic microbes and the termites themselves digest wood harmonically and synergistically (Brune, 2014). Disrupting this bacterial symbiosis with antibiotics significantly affects the normal physiology of termites (Rosengaus et al., 2011). As termites are small, their body temperature is greatly affected by the environment and the symbiotic microbes will also be exposed to the low temperature. It is unknown how symbiotic bacteria survive at low temperatures or how they maintain their essential support for survival of the termite.

The cellulose digestive system of termites using cellulase is complex (Lee et al., 2010). The termite digestive system produces endo- $\beta$-glucanase, which is an endotype cellulase, secreted in the mouth (Watanabe and Tokuda, 2010). However, lower termites require additional cellulases and many other enzymes from symbiotic microbes to fully digest wood (Brune, 2014). Lower termites cannot survive on wood alone without these symbiotic microbes, protozoa, bacteria, and archaea. In a previous study, 16 symbiotic bacteria were isolated from R. speratus KMT001 (Cho et al., 2010a). All of the strains had only cellobiohydrolase and $\beta$-glucosidase activities but no endo- $\beta$-glucanase activity. Considering that symbiotic bacteria have been isolated from the termite hindgut, we hypothesized that the loss of endo- $\beta$-glucanase activity was a consequence of symbiotic adaptation. The complete dependency of lower termites on symbiotic microbes for digesting wood may be due to diverse symbiotic biological functions (Brune, 2014; Peterson and Scharf, 2016). Considering the diverse habitats of termites and the requirements of symbiotic microbes, the symbiotic microbial population must change according to the termite's habitat.

In this study, we investigated the change in the symbiotic bacteria population in the lower termite, $R$. speratus KMT001, from Bukhan Mountain according to a change in temperature, particularly low temperature. The results will provide clues as to how lower termites receive support from symbiotic microbes and how they survive low temperatures.

\section{MATERIALS and METHODS}

\subsection{Purification of chromosomal DNA from symbiotic bacteria}

Lower termites, Reticulitermes speratus KMT001 (Cho et al., 2010b), were collected from Bukhan Mountain, Seoul, Korea; 50 worker termites were grown at $4{ }^{\circ} \mathrm{C}, 10^{\circ} \mathrm{C}, 15^{\circ} \mathrm{C}, 22^{\circ} \mathrm{C}$, and $26^{\circ} \mathrm{C}$ for 14 days, and their guts were extracted with tweezers (Kim et al., 2010). The termite gut was extracted at the same temperature as the growing conditions for the sample to maintain the bacterial flora. The extracted gut was suspended in $250 \mu \mathrm{l}$ of $50 \mathrm{mM}$ EDTA (pH 8.0) and $50 \mu \mathrm{l}$ of $10 \mathrm{~g} / \mathrm{l}$ lysozyme and incubated at $37^{\circ} \mathrm{C}$ for $1 \mathrm{~h}$. The supernatant was removed after $1 \mathrm{~min}$ centrifugation at 12,300 relative centrifugal force (RCF). Chromosomal DNA was purified with the MG Genomic DNA purification Kit (MGmed, Inc., Seoul, Korea). The AL buffer (300 $\mu$ l) was added to the pellet and resuspended by gentle pipetting. The mixture was incubated at $80^{\circ} \mathrm{C}$ for $5 \mathrm{~min}$. After cooling to room temperature, $1.5 \mu \mathrm{l}$ RNase A solution was added, mixed five times by inversion, and incubated in a $37^{\circ} \mathrm{C}$ water 
Symbiotic Bacterial Flora Changes in Response to Low Temperature in Reticulitermes speratus KMT001

bath for $1 \mathrm{~h}$. After cooling to room temperature, 100 $\mu \mathrm{l}$ PP buffer was added, mixed by vigorous vortexing for $20 \mathrm{sec}$, and incubated in ice for $5 \mathrm{~min}$. After centrifugation at 12,300 RCF for $3 \mathrm{~min}$, the supernatant was transferred to a $1.5 \mathrm{ml}$ Eppendorf tube containing $300 \mu \mathrm{l}$ isopropanol. After centrifugation at 12,300 RCF for $1 \mathrm{~min}$, the supernatant was removed, $300 \mu \mathrm{l}$ of $70 \%$ ethanol was added at $4^{\circ} \mathrm{C}$, and mixed by inversion several times. After centrifugation at 12,300 RCF for $1 \mathrm{~min}$, the supernatant was removed again, and the remaining ethanol was evaporated. The dried chromosomal DNA was rehydrated with $100 \mu \mathrm{l}$ distilled water in a $65^{\circ} \mathrm{C}$ water bath for $1 \mathrm{~h}$. Two independent chromosomal DNA samples were prepared for each termite growth temperature.

\subsection{Metagenomics analysis}

A metagenomics analysis was performed by Macrogen Co. (Seoul, Korea). The libraries were prepared using polymerase chain reaction (PCR) according to the Rapid Library Preparation Method Manual (454 Life Sciences Corp., Branford, CT, USA). The libraries were quantified using the Picogreen assay (Ahn et al., 1996) and Victor3 (PerkinElmer, Inc., Waltham, MA, USA). Emulsion-based clonal amplification (emPCR amplification), corresponding to clonal amplification of the purified library, was carried out using the GS FLX Titanium MV emPCR Kit (454 Life Sciences Co.). Briefly, the library was immobilized on DNA capture beads. The library beads were added to a mixture of amplification mix and oil and shaken vigorously on a TissueLyser II (Qiagen Korea Ltd., Seoul, Korea) to create "micro-reactors" containing the amplification mix and a single bead. The emulsion was dispensed into a 96-well plate, and the PCR amplification program was run according to the manufacturer's recommendations. A $20 \mathrm{ng}$ aliquot of each sample DNA was used for a $50 \mu$ PCR reaction.
The 27F (5'-GAGTTTGATCMTGGCTCAG-3') and 518R (5'-WTTACCGCGGCTGCTGG-3') 16S universal primers were used to amplify the 16s rRNA gene. The FastStart High Fidelity PCR System (Roche Diagnostics, Seoul, Korea) was used for the PCR analysis under the following conditions: $94^{\circ} \mathrm{C}$ for 3 min, followed by 35 cycles of $94^{\circ} \mathrm{C}$ for $15 \mathrm{sec}, 55^{\circ} \mathrm{C}$ for $45 \mathrm{sec}, 72^{\circ} \mathrm{C}$ for $1 \mathrm{~min}$, and a final elongation step at $72^{\circ} \mathrm{C}$ for $8 \mathrm{~min}$. After PCR, the product was purified using AMPure beads (Beckman Coulter Korea Ltd., Seoul, Korea) and sequenced by next generation sequencing using the 454 Genome Sequencer-FLX plus (Roche Diagnostics). Each sample was loaded in one region of a $70 \mathrm{~mm} \times 75 \mathrm{~mm}$ PicoTiter plate (454 Life Sciences Co.) fitted with an 8-lane gasket.

\subsection{Selection of $16 \mathrm{~S}$ rRNAs and taxonomic assignments}

All sequence reads were compared to the Silva rRNA database. Sequence reads with a similar sequence and an E-value $<0.01$ were admitted as partial 16S rRNA sequences. Less than $1 \%$ was non-16S rRNA sequence reads. The taxonomic assignments of the sequenced reads were carried out using the Taxonomy Databases of National Center for Biotechnology Information. The five most similar sequences for each sequence read were found in the database using their bit score and E-value from the BLAST program. The Needleman-Winch global alignment algorithm was used to find the optimum alignment of the two sequences along their entire length. Pairwise global alignment was performed on selected candidate hits to identify the best aligned hit. The taxonomy of the sequence with the highest similarity was assigned to the sequence read. Taxonomy was assigned to species with $>97 \%$ similarity, to genera with $94 \%$ similarity, to families with $90 \%$ similarity, to orders with $85 \%$ similarity, to classes with $80 \%$ similarity, and to phyla with $75 \%$ similarity. 


\subsection{Operational taxonomic unit (OTU) analysis for community richness}

CD-HIT-OTU and Mothur software (Needleman and Wunsch, 1970) was used for clustering. The ShannonWeaver diversity index and Simpson's index were used to determine species diversity in the microbial communities.

\section{5. $\beta$-glucosidase activity assay}

$\beta$-glucosidase activity was measure according to a previous study (Inoue et al., 1997) with a few modifications. The bacterial strains from the previous study (Cho et al., 2010a) were cultured in YP-CMC media $(0.8 \%$ peptone, $0.2 \%$ yeast extract, $0.5 \%$ potassium phosphate monobasic, $0.5 \%$ potassium phosphate dibasic, 2\% carboxymethyl cellulose, and 0.025\% antiform) for seven days with $200 \mathrm{rpm}$ shaking at the indicated temperature. A $100 \mu \mathrm{l}$ aliquot of the culture supernatant was mixed with $800 \mu \mathrm{l}$ of $0.1 \mathrm{M}$ sodium acetate buffer (pH 5.5) and $100 \mu \mathrm{l}$ of $10 \mathrm{mM}$ $\rho$-nitrophenyl- $\beta$-D-glucopyranoside, incubated at $50^{\circ} \mathrm{C}$ for $15 \mathrm{~min}$, and the reaction was stopped by mixing $100 \mu \mathrm{l} 2 \mathrm{M}$ sodium carbonate. Absorbance was measured at a wavelength of $405 \mathrm{~nm}$ and the amount of $\rho$-nitrophenol produced was calculated using a $\rho$ -nitrophenol standard curve. One unit of activity was defined as the amount of $\beta$-glucosidase activity that generated $1 \mu \mathrm{mol} \rho$-nitrophenol/min. Relative activity was calculated based on the highest activity of the strain among the tested temperatures.

\subsection{Changes in growth at different temperatures}

The strains were inoculated in $100 \mathrm{ml}$ YP-CMC media and cultured at the indicated temperatures with 250 rpm shaking. Cell density was estimated by measuring absorbance at $600 \mathrm{~nm}$ at the indicated times. The growth curve was drawn as a semi-logarithmic plot, and the doubling times of the strains at each temperature were calculated based on this semi-logarithmic plot.

\section{RESULTS and DISCUSSION}

\subsection{Change in gut bacterial population by temperature}

The population studies of symbiotic bacteria according to changes in termite growing temperature identified different predominant phylogenetic bacterial groups (Supplementary Tables 1-6). At the class level, Elusimicrobia was the predominant population at $22^{\circ} \mathrm{C}$ and Gammaproteobacteria was predominant at $4^{\circ} \mathrm{C}$ (Supplementary Table 3). Enterobacteriales and Enterobacteriaceae were the predominant order and family of bacteria at $4^{\circ} \mathrm{C}$, respectively (Supplementary Tables 4 and 5, respectively). Aestuariimicrobium, Citrobacter, Lactococcus, Serratia, and Treponema were the main genera at $4^{\circ} \mathrm{C}$ (Supplementary Table 6). All five major genera were representative examples of the four predominant phyla at $4^{\circ} \mathrm{C}$.

The changes in the six major populations at the phylum level with the unknown strains were selected from Supplementary Table 2 and drawn in Fig. 1. The proportions of Actinobacter, Firmicutes, Proteobacteria, and Spirochaetes increased at $4{ }^{\circ} \mathrm{C}$ and $10^{\circ} \mathrm{C}$, whereas those of Bacteroidetes and Elusimicrobia increased at $22^{\circ} \mathrm{C}$ and $26^{\circ} \mathrm{C}$ compared to $4^{\circ} \mathrm{C}$. The salient phylum was Elusimicrobia. The mean proportions of the Elusimicrobia populations at $22^{\circ} \mathrm{C}$ and $26^{\circ} \mathrm{C}$ increased more than 12-fold from the mean proportions observed at $4^{\circ} \mathrm{C}$ and $10^{\circ} \mathrm{C}$. The decrease in the proportion of many other phyla at $22^{\circ} \mathrm{C}$ and $26^{\circ} \mathrm{C}$ appeared to be due to the increase in the proportion of Elusimicrobia.

All phyla mentioned above were identified in previous studies (Ohkuma and Kudo, 1996; Hongoh et al., 2003; Yang et al., 2005). The termite Group 


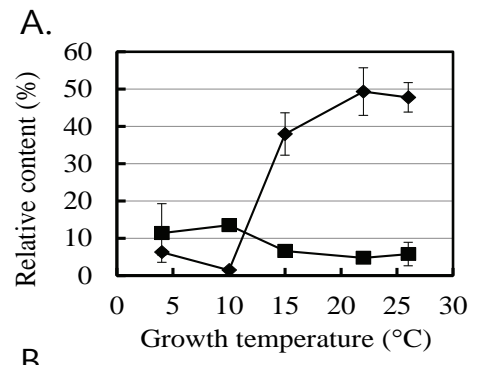

B.

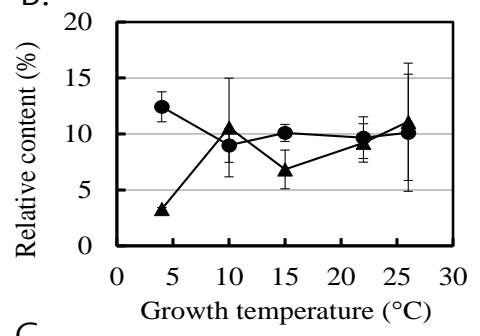

C.

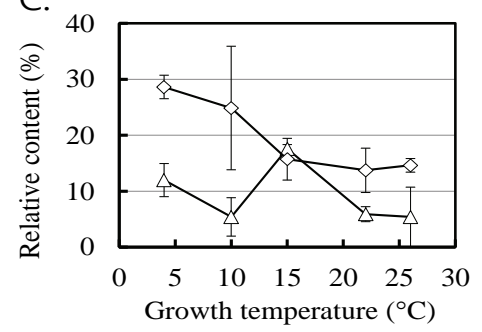

Fig. 1. Changes in the proportions of six major symbiotic bacteria phyla in Reticulitermes speratus KMT001 based on temperature. The six major phyla were: Spirochaetes ( $\square$ in A), Elusimicrobia $(>$ in A), Bacteroidetes ( $\boldsymbol{\Delta}$ in $\mathrm{B}$ ), Actinobacteria ( $\boldsymbol{O}$ in $\mathrm{B}$ ), Proteobacteria ( $\diamond$ in $C$ ), and Firmicutes ( $\triangle$ in $C$ ). The values are means of two independent experiments.

I phylum has been identified as symbiotic bacteria in the hindgut of the lower termite Reticulitermes speratus (Ohkuma and Kudo, 1996) and renamed phylum Elusimicrobia (Geissinger et al., 2009). Elusimicrobia are endosymbionts of symbiotic flagellate protists in termites and the major bacteria among symbiotic bacteria in the termite gut (Yang et al., 2005). Fig. 1 confirms that the majority of the termite symbiotic bacteria were Elusimicrobia only at temperatures $\geq 15^{\circ} \mathrm{C}$. Elusimicrobia was not the main phylum in the termite

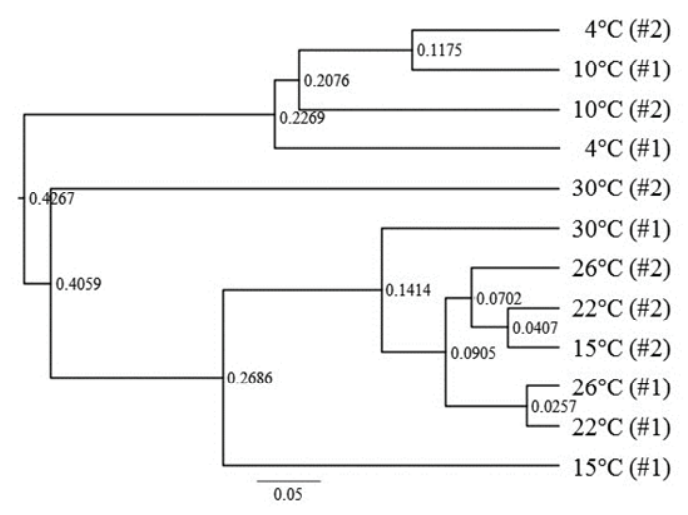

Fig. 2. Operational taxonomic unit (OTU) analysis for community richness. The symbiotic bacteria flora samples in the termites at each temperature were taken independently and are shown as \#1 and \#2 for each sample. Numbers on the nodes at branch separation represent node depths. The ruler bar at the bottom indicates 0.05 relative depth.

gut at $4^{\circ} \mathrm{C}$ and $10^{\circ} \mathrm{C}$. Because Elusimicrobia is associated with protists (Yang et al., 2005), it was expected that the change in the Elusimicrobia population would reflect the population change in protists. Growth of protists is significantly inhibited at temperatures $<15^{\circ} \mathrm{C}$ (Rose and Caron, 2007), supporting the hypothesis that the decrease in the Elusimicrobia population was due to the reduced number of host flagellate protists at $4^{\circ} \mathrm{C}$ and $10^{\circ} \mathrm{C}$. Growth of symbiotic protists and endosymbiotic Elusimicrobia may be inhibited when temperature of the termites is low, such as $4^{\circ} \mathrm{C}$ and $10^{\circ} \mathrm{C}$. The drastic decrease in the Elusimicrobia population may be the main contributor to the increase in the populations of other bacteria at $4^{\circ} \mathrm{C}$ and $10^{\circ} \mathrm{C}$. Notably, the unidentified phylum of bacteria in Supplementary Table 2 (shown as 'The rest') was $>25 \%$ of the total population at $4^{\circ} \mathrm{C}$ and $10^{\circ} \mathrm{C}$. Because most studies on symbiotic bacteria were performed at room temperature or higher (Ohkuma and Kudo, 1996; Hongoh et al., 2003; Yang et al., 2005; Herlemann et al., 2007), many of the symbiotic bacteria 
found at low temperatures in this study may not have been known.

The beta diversity results in Fig. 2 show that the symbiotic bacterial populations in the termite gut at $4^{\circ} \mathrm{C}$ and $10^{\circ} \mathrm{C}$ were quite different from those observed at $\geq 15^{\circ} \mathrm{C}$. Therefore, the beta diversity analysis of the metagenomics results supports the population analysis at the phylum level in Fig. 1.

\subsection{Symbiotic bacteria supporting termites at low temperature}

Lower termites growing at low temperatures still need support from symbiotic microbes to survive. The Elusimicrobia populations at $4^{\circ} \mathrm{C}$ and $10^{\circ} \mathrm{C}$ decreased dramatically, and it is expected that the number of protists also decreased. Therefore, termites require symbiotic support from other microbes. In a previous study, 16 bacteria were isolated from the lower termite R. speratus KMT001 (Cho et al., 2010a). All produced cellobiohydrolase and $\beta$-glucosidase but not endo- $\beta$ glucanase. In this study, we tested the temperature effect on $\beta$-glucosidase production by the isolated strains. The 16 strains tested showed the activity of on $\beta$-glucosidase at various temperature and the results of four representative strains of them were shown in Fig. 3. Elizabethkingia sp. BM10, Bacillus sp. NT4, Serratia sp. PT1B, and Serratia sp. NT3 had maximum $\beta$-glucosidase activity when grown at $10^{\circ} \mathrm{C}, 20^{\circ} \mathrm{C}, 25^{\circ} \mathrm{C}$, and $30^{\circ} \mathrm{C}$, respectively, indicating that $R$. speratus KMT001 has broad bacterial diversity that produced $\beta$-glucosidase within the temperature range of the termite habitat, including $10^{\circ} \mathrm{C}$. The interesting observation was $\beta$-glucosidase production by Elizabethkingia sp. BM10. An increase in temperature by $5^{\circ} \mathrm{C}$ from the temperature that yielded the highest $\beta$-glucosidase activity reduced $\beta$-glucosidase production by more than $40 \%$, suggesting that Elizabethkingia sp. BM10 is specialized to produce $\beta$-glucosidase at $10^{\circ} \mathrm{C}$ and that this strain supports cellulose

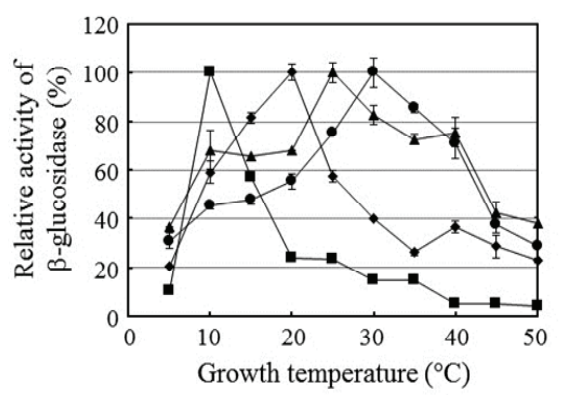

Fig. 3. Effect of temperature on $\beta$-glucosidase production by four symbiotic bacteria from Reticulitermes speratus KMT001. Relative $\beta$-glucosidase activity of culture media was calculated based on the maximum activity of the tested strain after a 7-day culture. The four strains were Elizabethkingia sp. BM10 (ם), Bacillus sp. NT4 $(\diamond)$, Serratia sp. PT1B ( $\Delta)$, and Serratia sp. NT3 ( ). Values are means of three independent experiments.

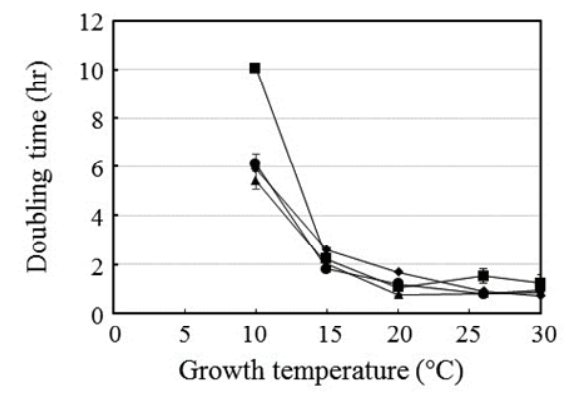

Fig. 4. Effect of temperature on the doubling time of the four strains: Elizabethkingia sp. BM10 (ם), Bacillus sp. NT4 $(\diamond)$, Serratia sp. PT1B $(\boldsymbol{\Delta})$, and Serratia sp. NT3 ( ). The growth curve was observed at the indicated temperature, and the doubling times were calculated during the exponential phase. Values are means of two independent experiments, except that for Elizabethkingia sp. BM10 whose mean value was from three independent experiments.

digestion in the termite gut at low temperatures.

The growth rates of four representative isolated symbiotic bacteria were tested (Fig. 4). The doubling times of the strains were similar at most of the temperatures tested, except $10^{\circ} \mathrm{C}$, at which the doubling 
time of Elizabethkingia sp. BM10 was almost twice that of the other three strains. This finding indicates that the growth rate of Elizabethkingia sp. BM10 was lower than that of the other strains. The slow growth rate of Elizabethkingia sp. BM10 can be explained by the strong $\beta$-glucosidase production at $10^{\circ} \mathrm{C}$ (Kafri et al., 2016).

This study showed a dramatic change in the symbiotic bacterial flora of $R$. speratus KMT001 at low temperatures of $4{ }^{\circ} \mathrm{C}$ and $10^{\circ} \mathrm{C}$. More than $25 \%$ of the bacteria in the metagenomics analysis were unknown strains, suggesting that more intense studies on symbiotic bacteria of termites are required at low temperature. Elizabethkingia sp. BM10 produced maximal $\beta$-glucosidase levels at $10^{\circ} \mathrm{C}$, which is an unusual temperature for $\beta$-glucosidase production. We suggest that Elizabethkingia sp. BM10 is one of the strains supporting cellulose digestion in termites at low temperature.

\section{CONCLUSION}

Termites are harmful insects causing large economic losses and also models for the biological degradation system of woods. Lower termites require a support of symbiotic microbes in the digestion. However, their symbiosis at low temperature has not been studied well. In this study, we showed a significant change of symbiotic bacterial flora by low temperature and present one example of isolated bacteria strain supporting the symbiosis at low temperature. This study provides clues how termites can survive with symbiotic supports and demonstrates the symbiotic adaptation of bacterial flora in the termite guts at low temperature.

\section{ACKNOWLEDGMENT}

This study was carried out with the support of 'R\&D Program for Forest Science Technology (Project No. 2013070E10-1819-AA03)' provided by Korea Forest Service (Korea Forestry Promotion Institute).

\section{REFERENCES}

Ahn, S.J., Costa, J., Emanuel, J.R. 1996. PicoGreen quantitation of DNA: effective evaluation of samples pre- or post-PCR. Nucleic Acids Research 24(13): 2623-2625.

Brune, A. 2014. Symbiotic digestion of lignocellulose in termite guts. Nature Reviews Microbiology 12(3): 168-180.

Brune, A., Ohkuma, M. 2011. Role of the termite gut microbiota in symbiotic digestion. In: Biology of termites: A modern synthesis. Ed. by Bignell D.E., Roisin Y., and Lo N., Springer. pp. 439-475.

Cho, M.-J., Kim, Y.-H., Shin, K., Kim, Y.-K., Kim, Y.-S., Kim, T.-J. 2010a. Symbiotic adaptation of bacteria in the gut of Reticulitermes speratus: Low endo- $\beta$-1,4-glucanase activity. Biochemical and Biophysical Research Communications 395(3): 432-435.

Cho, M.J., Shin, K., Kim, Y.-K., Kim, Y.-S., Kim, T.-J. 2010b. Phylogenetic analysis of Reticulitermes speratus using the mitochondrial cytochrome $\mathrm{C}$ oxidase subunit I gene. Journal of the Korean Wood Science and Technology 38(2): 135-139.

Cleveland, L.R. 1923. Symbiosis between termites and their intestinal protozoa. Proceedings of the National Academy of Sciences of the United States of America 9(12): 424-428.

Evans, T.A., Forschler, B.T., Grace, J.K. 2013. Biology of invasive termites: A worldwide review. Annual Review of Entomology 58(1): 455-474.

Geissinger, O., Herlemann, D.P.R., Mörschel, E., Maier, U.G., Brune, A. 2009. The ultramicrobacterium "Elusimicrobium minutum" gen. nov., sp. nov., the first cultivated representative of the termite group 1 phylum. Applied and Environmental Microbiology 75(9): 2831-2840.

Ghaly, A.E., Edwards, S. 2011. Termite damage to buildings: Nature of attacks and preventive construction methods. American Journal of Engineering and Applied Sciences 4(2): 187-200. 
Herlemann, D.P.R., Geissinger, O., Brune, A. 2007. The termite group I phylum is highly diverse and widespread in the environment. Applied and Environmental Microbiology 73(20): 6682-6685.

Hongoh, Y., Ohkuma, M., Kudo, T. 2003. Molecular analysis of bacterial microbiota in the gut of the termite Reticulitermes speratus (Isoptera; Rhinotermitidae). FEMS Microbiology Ecology 44(2): 231-242.

Inoue, T., Murashima, K., Azuma, J.I., Sugimoto, A., Slaytor, M. 1997. Cellulose and xylan utilisation in the lower termite Reticulitermes speratus. Journal of Insect Physiology 43(3): 235-242.

Jung, H.-S., Choi, Y., Oh, J.-H., Lim, G.-H. 2002. Recent trends in temperature and precipitation over South Korea. International Journal of Climatoogy 22: 1327-1337.

Kafri, M., Metzl-Raz, E., Jona, G., Barkai, N. 2016. The cost of protein production. Cell Reports 14(1): 22-31.

Kim, M.J., Choi, Y.S., Lee, J., Kim, J.J., Kim, G.H. 2012. Molecular characteristics of subterranean termites of the genus Reticulitermes (Isoptera: Rhinotermitidae) from Korea. Annals of the Entomological Society of America 105(1): 97-102.

Kim, S.H., Chung, Y.J. 2017. Ingestion toxicity of fipronil on Reticulitermes speratus kyushuensis (Isoptera: Rhinotermitidae) and its applicability as a termite bait. Journal of the Korean Wood Science and Technology 45(2): 159-167.

Kim, Y.H., Lee, Y.M., Kim, Y.S., Cho, M.J., Shin, K. 2010. Cellulase production in the digestive organs of Reticulitermes speratus, a native termite from Milyang Korea. Journal of the Korean Wood Science and Technology 38(5): 421-428.

Mun, S.P., Nicholas, D.D. 2017. Effect of proanthocyanidin-rich extracts from Pinus radiata bark on termite feeding deterrence. Journal of the Korean Wood Science and Technology 45(6): 720-727.

Needleman, S.B., Wunsch, C.D. 1970. A general method applicable to the search for similarities in the amino acid sequence of two proteins. Journal of Molecular Biology 48(3): 443-453.

Ohkuma, M., Kudo, T. 1996. Phylogenetic diversity of the intestinal bacterial community in the termite Reticulitermes speratus. Applied and Environmental Microbiology 62(2): 461-468.

Park, Y.C., Kitade, O., Schwarz, M., Kim, J.P., Kim, W. 2006. Intraspecific molecular phylogeny, genetic variation and phylogeography of Reticulitermes speratus (Isoptera: Rhinotermitidae). Molecular Cell 21(1): 89-103.

Peterson, B.F., Scharf, M.E. 2016. Lower termite associations with microbes: Synergy, protection, and interplay. Frontiers in Microbiology 7(422).

Peterson, C., Wagner, T.L., Mulrooney, J.E., Shelton, T.G. 2006. Subterranean termites - their prevention and control in buildings. Home and Garden Bulletin 64. pp. 38.

Rose, J.M., Caron, D.A. 2007. Does low temperature constrain the growth rates of heterotrophic protists? Evidence and implications for algal blooms in cold waters. Limnology and Oceanography 52(2): 886-895.

Rosengaus, R.B., Zecher, C.N., Schultheis, K.F., Brucker, R.M., Bordenstein, S.R. 2011. Disruption of the termite gut microbiota and its prolonged consequences for fitness. Applied and Environmental Microbiology 77(13): 4303-4312.

Shi, Y., Huang, Z., Han, S., Fan, S., Yang, H. 2015. Phylogenetic diversity of Archaea in the intestinal tract of termites from different lineages. Journal of Basic Microbiology 55(8): 1021-1028.

Watanabe, H., Tokuda, G. 2010. Cellulolytic systems in insects. Annual Review of Entomology 55(1): 609-632.

Yang, H., Schmitt-Wagner, D., Stingl, U., Brune, A. 2005. Niche heterogeneity determines bacterial community structure in the termite gut (Reticulitermes santonensis). Environmental Microbiology 7(7): 916-932. 
Supplemental Table 1. Metagenomics analysis of the temperature effect on the symbiotic bacterial population of Reticulitermes speratus KMT001 at the superkingdom level.

\begin{tabular}{|c|c|c|c|c|c|}
\hline \multirow{2}{*}{ Superkingdom } & \multicolumn{5}{|c|}{ Relative content (\%) and standard deviation in parenthesis } \\
\hline & $4^{\circ} \mathrm{C}$ & $10^{\circ} \mathrm{C}$ & $15^{\circ} \mathrm{C}$ & $22^{\circ} \mathrm{C}$ & $26^{\circ} \mathrm{C}$ \\
\hline Bacteria & $100( \pm 0.00)$ & $100( \pm 0.00)$ & $100( \pm 0.00)$ & $100( \pm 0.00)$ & $100( \pm 0.00)$ \\
\hline The rest & $0( \pm 0.00)$ & $0( \pm 0.00)$ & $0( \pm 0.00)$ & $0( \pm 0.00)$ & $0( \pm 0.00)$ \\
\hline
\end{tabular}

Supplemental Table 2. Metagenomics analysis of the temperature effect on the symbiotic bacterial population of Reticulitermes speratus KMT001 at the phylum level.

\begin{tabular}{|c|c|c|c|c|c|}
\hline \multirow{2}{*}{ Phylum } & \multicolumn{5}{|c|}{ Relative content (\%) and standard deviation in parenthesis } \\
\hline & $4^{\circ} \mathrm{C}$ & $10^{\circ} \mathrm{C}$ & $15^{\circ} \mathrm{C}$ & $22^{\circ} \mathrm{C}$ & $26^{\circ} \mathrm{C}$ \\
\hline Acidobacteria & $0.00( \pm 0.00)$ & $0.00( \pm 0.00)$ & $0.00( \pm 0.00)$ & $0.23( \pm 0.33)$ & $0.08( \pm 0.11)$ \\
\hline Actinobacteria & $11.39( \pm 7.85)$ & $13.52( \pm 1.47)$ & $6.58( \pm 1.54)$ & $4.75( \pm 0.73)$ & $5.76( \pm 3.16)$ \\
\hline Bacteroidetes & $3.30( \pm 0.12)$ & $10.58( \pm 4.41)$ & $6.83( \pm 1.73)$ & $9.20( \pm 1.71)$ & $11.09( \pm 5.24)$ \\
\hline Chlorobi & $0.06( \pm 0.08)$ & $0.00( \pm 0.00)$ & $0.00( \pm 0.00)$ & $0.03( \pm 0.04)$ & $0.00( \pm 0.00)$ \\
\hline Cyanobacteria & $0.00( \pm 0.00)$ & $0.01( \pm 0.01)$ & $0.10( \pm 0.06)$ & $0.06( \pm 0.07)$ & $0.00( \pm 0.00)$ \\
\hline Deinococcus-Thermus & $0.00( \pm 0.00)$ & $0.00( \pm 0.00)$ & $0.03( \pm 0.04)$ & $0.30( \pm 0.31)$ & $0.00( \pm 0.00)$ \\
\hline Elusimicrobia & $6.26( \pm 0.70)$ & $1.47( \pm 0.40)$ & $37.93( \pm 5.68)$ & $49.31( \pm 6.38)$ & $47.76( \pm 3.94)$ \\
\hline Firmicutes & $12.43( \pm 1.34)$ & $8.99( \pm 1.51)$ & $10.09( \pm 0.77)$ & $9.67( \pm 1.86)$ & $10.11( \pm 5.23)$ \\
\hline Fusobacteria & $0.00( \pm 0.00)$ & $0.00( \pm 0.00)$ & $0.00( \pm 0.00)$ & $0.03( \pm 0.02)$ & $0.00( \pm 0.00)$ \\
\hline Planctomycetes & $0.14( \pm 0.08)$ & $0.18( \pm 0.01)$ & $0.04( \pm 0.06)$ & $0.11( \pm 0.07)$ & $0.03( \pm 0.04)$ \\
\hline Proteobacteria & $28.63( \pm 2.10)$ & $24.87( \pm 11.05)$ & $15.73( \pm 3.71)$ & $13.75( \pm 3.97)$ & $14.64( \pm 1.21)$ \\
\hline Spirochaetes & $11.99( \pm 2.97)$ & $5.41( \pm 3.42)$ & $17.58( \pm 0.75)$ & $5.90( \pm 1.35)$ & $5.42( \pm 5.33)$ \\
\hline Synergistetes & $0.44( \pm 0.31)$ & $0.65( \pm 0.30)$ & $0.88( \pm 0.03)$ & $0.84( \pm 0.16)$ & $0.31( \pm 0.21)$ \\
\hline Tenericutes & $0.46( \pm 0.10)$ & $0.27( \pm 0.00)$ & $0.36( \pm 0.13)$ & $0.80( \pm 0.97)$ & $0.26( \pm 0.22)$ \\
\hline Verrucomicrobia & $0.22( \pm 0.15)$ & $0.07( \pm 0.10)$ & $0.21( \pm 0.21)$ & $0.17( \pm 0.17)$ & $0.35( \pm 0.25)$ \\
\hline The rest & $24.68( \pm 4.46)$ & $33.97( \pm 2.38)$ & $3.63( \pm 1.20)$ & $4.84( \pm 1.19)$ & $4.18( \pm 0.46)$ \\
\hline
\end{tabular}

Supplemental Table 3. Metagenomics analysis of the temperature effect on the symbiotic bacterial population of Reticulitermes speratus KMT001 at the class level.

\begin{tabular}{crrrrr}
\hline Class & \multicolumn{5}{c}{ Relative content $(\%)$ and standard deviation in parenthesis } \\
\cline { 2 - 6 } & \multicolumn{1}{c}{$4^{\circ} \mathrm{C}$} & \multicolumn{1}{c}{$10^{\circ} \mathrm{C}$} & \multicolumn{1}{c}{$15^{\circ} \mathrm{C}$} & \multicolumn{1}{c}{$22^{\circ} \mathrm{C}$} & $26^{\circ} \mathrm{C}$ \\
\hline \hline Acidobacteria & $0.00( \pm 0.00)$ & $0.00( \pm 0.00)$ & $0.00( \pm 0.00)$ & $0.23( \pm 0.33)$ & $0.08( \pm 0.11)$ \\
Actinobacteria & $11.39( \pm 7.85)$ & $13.52( \pm 1.47)$ & $6.58( \pm 1.54)$ & $4.75( \pm 0.73)$ & $5.76( \pm 3.16)$ \\
Alphaproteobacteria & $4.77( \pm 0.46)$ & $2.36( \pm 1.80)$ & $10.56( \pm 0.95)$ & $9.70( \pm 4.96)$ & $8.91( \pm 0.82)$ \\
Bacilli & $10.47( \pm 2.03)$ & $4.12( \pm 0.32)$ & $5.93( \pm 1.05)$ & $7.15( \pm 1.38)$ & $7.24( \pm 3.80)$ \\
Bacteroidia & $3.29( \pm 0.11)$ & $10.39( \pm 4.32)$ & $6.56( \pm 1.59)$ & $8.91( \pm 1.31)$ & $10.80( \pm 5.50)$ \\
Betaproteobacteria & $1.38( \pm 0.66)$ & $5.99( \pm 6.23)$ & $4.06( \pm 2.38)$ & $2.07( \pm 1.05)$ & $1.01( \pm 0.87)$ \\
Chlorobia & $0.06( \pm 0.08)$ & $0.00( \pm 0.00)$ & $0.00( \pm 0.00)$ & $0.03( \pm 0.04)$ & $0.00( \pm 0.00)$ \\
Clostridia & $1.88( \pm 0.74)$ & $4.85( \pm 1.19)$ & $3.94( \pm 0.32)$ & $2.49( \pm 0.46)$ & $2.84( \pm 1.47)$ \\
Deltaproteobacteria & $0.29( \pm 0.10)$ & $0.08( \pm 0.00)$ & $0.73( \pm 0.48)$ & $0.41( \pm 0.18)$ & $0.07( \pm 0.07)$ \\
Elusimicrobia & $6.26( \pm 0.70)$ & $1.47( \pm 0.40)$ & $37.93( \pm 5.68)$ & $49.31( \pm 6.38)$ & $47.76( \pm 3.94)$ \\
Epsilonproteobacteria & $0.19( \pm 0.17)$ & $0.28( \pm 0.16)$ & $0.10( \pm 0.08)$ & $0.03( \pm 0.04)$ & $0.00( \pm 0.00)$ \\
Erysipelotrichi & $0.08( \pm 0.05)$ & $0.02( \pm 0.00)$ & $0.22( \pm 0.04)$ & $0.03( \pm 0.02)$ & $0.03( \pm 0.04)$ \\
Flavobacteria & $0.01( \pm 0.02)$ & $0.19( \pm 0.09)$ & $0.27( \pm 0.15)$ & $0.29( \pm 0.40)$ & $0.29( \pm 0.26)$ \\
Fusobacteria & $0.00( \pm 0.00)$ & $0.00( \pm 0.00)$ & $0.00( \pm 0.00)$ & $0.03( \pm 0.02)$ & $0.00( \pm 0.00)$ \\
Gammaproteobacteria & $22.00( \pm 0.92)$ & $16.16( \pm 18.91)$ & $0.27( \pm 0.19)$ & $1.54( \pm 0.27)$ & $4.64( \pm 1.19)$ \\
Mollicutes & $0.46( \pm 0.10)$ & $0.27( \pm 0.00)$ & $0.36( \pm 0.13)$ & $0.80( \pm 0.97)$ & $0.26( \pm 0.22)$ \\
Opitutae & $0.22( \pm 0.15)$ & $0.07( \pm 0.10)$ & $0.21( \pm 0.21)$ & $0.17( \pm 0.17)$ & $0.35( \pm 0.25)$ \\
Planctomycetacia & $0.14( \pm 0.08)$ & $0.17( \pm 0.03)$ & $0.04( \pm 0.05)$ & $0.09( \pm 0.09)$ & $0.03( \pm 0.04)$ \\
Sphingobacteria & $0.00( \pm 0.00)$ & $0.00( \pm 0.00)$ & $0.00( \pm 0.00)$ & $0.00( \pm 0.00)$ & $0.00( \pm 0.00)$ \\
Spirochaetes & $11.99( \pm 2.97)$ & $5.41( \pm 3.42)$ & $17.58( \pm 0.75)$ & $5.90( \pm 1.35)$ & $5.42( \pm 5.33)$ \\
Synergistia & $0.44( \pm 0.31)$ & $0.65( \pm 0.30)$ & $0.88( \pm 0.30)$ & $0.84( \pm 0.16)$ & $0.31( \pm 0.21)$ \\
The rest & $24.68( \pm 4.46)$ & $33.99( \pm 2.41)$ & $3.77( \pm 1.30)$ & $5.22( \pm 0.83)$ & $4.18( \pm 0.46)$ \\
\hline & & & &
\end{tabular}


Supplemental Table 4. Metagenomics analysis of the temperature effect on the symbiotic bacterial population of Reticulitermes speratus KMT001 at the order level.

\begin{tabular}{|c|c|c|c|c|c|}
\hline \multirow{2}{*}{ Order } & \multicolumn{5}{|c|}{ Relative content (\%) and standard deviation in parenthesis } \\
\hline & $4^{\circ} \mathrm{C}$ & $10^{\circ} \mathrm{C}$ & $15^{\circ} \mathrm{C}$ & $22^{\circ} \mathrm{C}$ & $26^{\circ} \mathrm{C}$ \\
\hline Acidobacteriales & $0.00( \pm 0.00)$ & $0.00( \pm 0.00)$ & $0.00( \pm 0.00)$ & $0.23( \pm 0.33)$ & $0.08( \pm 0.11)$ \\
\hline Actinomycetales & $11.21( \pm 7.85)$ & $13.43( \pm 1.49)$ & $6.49( \pm 1.51)$ & $4.69( \pm 0.75)$ & $5.69( \pm 3.08)$ \\
\hline Bacillales & $0.00( \pm 0.00)$ & $0.00( \pm 0.00)$ & $0.00( \pm 0.00)$ & $0.12( \pm 0.03)$ & $0.43( \pm 0.61)$ \\
\hline Bacteroidales & $3.29( \pm 0.11)$ & $10.39( \pm 4.32)$ & $6.56( \pm 1.59)$ & $8.91( \pm 1.31)$ & $10.80( \pm 5.50)$ \\
\hline Burkholderiales & $0.41( \pm 0.51)$ & $2.75( \pm 3.18)$ & $0.14( \pm 0.05)$ & $0.13( \pm 0.19)$ & $0.36( \pm 0.30)$ \\
\hline Campylobacterales & $0.19( \pm 0.17)$ & $0.28( \pm 0.16)$ & $0.10( \pm 0.08)$ & $0.03( \pm 0.04)$ & $0.00( \pm 0.00)$ \\
\hline Caulobacterales & $0.00( \pm 0.00)$ & $0.00( \pm 0.00)$ & $0.00( \pm 0.00)$ & $0.10( \pm 0.01)$ & $0.00( \pm 0.00)$ \\
\hline Chlorobiales & $0.06( \pm 0.08)$ & $0.00( \pm 0.00)$ & $0.00( \pm 0.00)$ & $0.03( \pm 0.04)$ & $0.00( \pm 0.00)$ \\
\hline Clostridiales & $1.88( \pm 0.74)$ & $4.85( \pm 1.19)$ & $3.94( \pm 0.32)$ & $2.49( \pm 0.46)$ & $2.84( \pm 1.47)$ \\
\hline Coriobacteriales & $0.18( \pm 0.00)$ & $0.09( \pm 0.02)$ & $0.08( \pm 0.03)$ & $0.07( \pm 0.02)$ & $0.07( \pm 0.08)$ \\
\hline Desulfovibrionales & $0.15( \pm 0.08)$ & $0.05( \pm 0.04)$ & $0.61( \pm 0.34)$ & $0.36( \pm 0.20)$ & $0.07( \pm 0.08)$ \\
\hline Elusimicrobiales & $0.00( \pm 0.00)$ & $0.04( \pm 0.06)$ & $0.03( \pm 0.04)$ & $0.01( \pm 0.01)$ & $0.00( \pm 0.00)$ \\
\hline Enterobacteriales & $22.00( \pm 0.92)$ & $15.79( \pm 19.23)$ & $0.03( \pm 0.04)$ & $1.45( \pm 0.31)$ & $4.20( \pm 1.78)$ \\
\hline Erysipelotrichales & $0.08( \pm 0.05)$ & $0.02( \pm 0.00)$ & $0.22( \pm 0.04)$ & $0.03( \pm 0.02)$ & $0.03( \pm 0.04)$ \\
\hline Flavobacteriales & $0.01( \pm 0.02)$ & $0.19( \pm 0.09)$ & $0.27( \pm 0.15)$ & $0.29( \pm 0.40)$ & $0.29( \pm 0.26)$ \\
\hline Fusobacteriales & $0.00( \pm 0.00)$ & $0.00( \pm 0.00)$ & $0.00( \pm 0.00)$ & $0.03( \pm 0.02)$ & $0.00( \pm 0.00)$ \\
\hline Lactobacillales & $10.47( \pm 2.03)$ & $4.12( \pm 0.32)$ & $5.93( \pm 1.05)$ & $7.03( \pm 1.41)$ & $6.81( \pm 3.19)$ \\
\hline Legionellales & $0.00( \pm 0.00)$ & $0.00( \pm 0.00)$ & $0.00( \pm 0.00)$ & $0.00( \pm 0.00)$ & $0.08( \pm 0.11)$ \\
\hline Mycoplasmatales & $0.46( \pm 0.10)$ & $0.27( \pm 0.00)$ & $0.36( \pm 0.13)$ & $0.80( \pm 0.97)$ & $0.26( \pm 0.22)$ \\
\hline Neisseriales & $0.08( \pm 0.05)$ & $2.55( \pm 3.61)$ & $0.02( \pm 0.01)$ & $0.19( \pm 0.14)$ & $0.03( \pm 0.04)$ \\
\hline Planctomycetales & $0.14( \pm 0.08)$ & $0.17( \pm 0.03)$ & $0.04( \pm 0.05)$ & $0.09( \pm 0.09)$ & $0.03( \pm 0.04)$ \\
\hline Pseudomonadales & $0.00( \pm 0.00)$ & $0.35( \pm 0.28)$ & $0.19( \pm 0.08)$ & $0.02( \pm 0.03)$ & $0.15( \pm 0.21)$ \\
\hline Rhizobiales & $0.00( \pm 0.00)$ & $0.04( \pm 0.06)$ & $0.07( \pm 0.10)$ & $0.10( \pm 0.12)$ & $0.17( \pm 0.03)$ \\
\hline Rhodocyclales & $0.90( \pm 0.20)$ & $0.69( \pm 0.56)$ & $3.89( \pm 2.43)$ & $1.75( \pm 1.10)$ & $0.63( \pm 0.61)$ \\
\hline Rhodospirillales & $0.25( \pm 0.13)$ & $0.16( \pm 0.01)$ & $0.31( \pm 0.10)$ & $0.57( \pm 0.63)$ & $0.15( \pm 0.02)$ \\
\hline Rickettsiales & $4.52( \pm 0.59)$ & $2.02( \pm 1.59)$ & $10.18( \pm 0.94)$ & $8.89( \pm 4.39)$ & $8.48( \pm 1.01)$ \\
\hline Sphingobacteriales & $0.00( \pm 0.00)$ & $0.00( \pm 0.00)$ & $0.00( \pm 0.00)$ & $0.00( \pm 0.00)$ & $0.00( \pm 0.00)$ \\
\hline Sphingomonadales & $0.00( \pm 0.00)$ & $0.14( \pm 0.16)$ & $0.00( \pm 0.00)$ & $0.03( \pm 0.04)$ & $0.12( \pm 0.17)$ \\
\hline Spirochaetales & $11.99( \pm 2.97)$ & $5.41( \pm 3.42)$ & $17.58( \pm 0.75)$ & $5.90( \pm 1.35)$ & $5.42( \pm 5.33)$ \\
\hline Synergistales & $0.44( \pm 0.31)$ & $0.65( \pm 0.30)$ & $0.88( \pm 0.30)$ & $0.84( \pm 0.16)$ & $0.31( \pm 0.21)$ \\
\hline Thermales & $0.00( \pm 0.00)$ & $0.00( \pm 0.00)$ & $0.03( \pm 0.04)$ & $0.30( \pm 0.31)$ & $0.00( \pm 0.00)$ \\
\hline Xanthomonadales & $0.00( \pm 0.00)$ & $0.02( \pm 0.03)$ & $0.05( \pm 0.07)$ & $0.07( \pm 0.00)$ & $0.21( \pm 0.27)$ \\
\hline The rest & $31.30( \pm 5.32)$ & $35.53( \pm 2.89)$ & $41.97( \pm 7.05)$ & $54.45( \pm 7.69)$ & $52.30( \pm 3.25)$ \\
\hline
\end{tabular}

Supplemental Table 5. Metagenomics analysis of the temperature effect on the symbiotic bacterial population of Reticulitermes speratus KMT001 at the family level.

\begin{tabular}{|c|c|c|c|c|c|}
\hline \multirow{2}{*}{ Family } & \multicolumn{5}{|c|}{ Relative content (\%) and standard deviation in parenthesis } \\
\hline & $4^{\circ} \mathrm{C}$ & $10^{\circ} \mathrm{C}$ & $15^{\circ} \mathrm{C}$ & $22^{\circ} \mathrm{C}$ & $26^{\circ} \mathrm{C}$ \\
\hline Acetobacteraceae & $0.00( \pm 0.00)$ & $0.00( \pm 0.00)$ & $0.00( \pm 0.00)$ & $0.08( \pm 0.11)$ & $0.05( \pm 0.07)$ \\
\hline Acidobacteriaceae & $0.00( \pm 0.00)$ & $0.00( \pm 0.00)$ & $0.00( \pm 0.00)$ & $0.23( \pm 0.33)$ & $0.08( \pm 0.11)$ \\
\hline Actinomycetaceae & $0.00( \pm 0.00)$ & $0.05( \pm 0.07)$ & $0.00( \pm 0.00)$ & $0.00( \pm 0.00)$ & $0.00( \pm 0.00)$ \\
\hline Alcaligenaceae & $0.00( \pm 0.00)$ & $0.00( \pm 0.00)$ & $0.00( \pm 0.00)$ & $0.00( \pm 0.00)$ & $0.04( \pm 0.06)$ \\
\hline Alicyclobacillaceae & $0.00( \pm 0.00)$ & $0.00( \pm 0.00)$ & $0.00( \pm 0.00)$ & $0.02( \pm 0.03)$ & $0.00( \pm 0.00)$ \\
\hline Aurantimonadaceae & $0.00( \pm 0.00)$ & $0.00( \pm 0.00)$ & $0.00( \pm 0.00)$ & $0.00( \pm 0.00)$ & $0.09( \pm 0.07)$ \\
\hline Bacillaceae & $0.00( \pm 0.00)$ & $0.00( \pm 0.00)$ & $0.00( \pm 0.00)$ & $0.00( \pm 0.00)$ & $0.19( \pm 0.26)$ \\
\hline Bradyrhizobiaceae & $0.00( \pm 0.00)$ & $0.04( \pm 0.06)$ & $0.02( \pm 0.02)$ & $0.08( \pm 0.09)$ & $0.04( \pm 0.05)$ \\
\hline Brucellaceae & $0.00( \pm 0.00)$ & $0.00( \pm 0.00)$ & $0.00( \pm 0.00)$ & $0.00( \pm 0.00)$ & $0.02( \pm 0.03)$ \\
\hline Burkholderiaceae & $0.00( \pm 0.00)$ & $0.00( \pm 0.00)$ & $0.04( \pm 0.06)$ & $0.13( \pm 0.19)$ & $0.09( \pm 0.08)$ \\
\hline
\end{tabular}


Symbiotic Bacterial Flora Changes in Response to Low Temperature in Reticulitermes speratus KMT001

Supplemental Table 5. (Continued)

\begin{tabular}{|c|c|c|c|c|c|}
\hline \multirow{2}{*}{ Family } & \multicolumn{5}{|c|}{ Relative content (\%) and standard deviation in parenthesis } \\
\hline & $4^{\circ} \mathrm{C}$ & $10^{\circ} \mathrm{C}$ & $15^{\circ} \mathrm{C}$ & $22^{\circ} \mathrm{C}$ & $26^{\circ} \mathrm{C}$ \\
\hline Caulobacteraceae & $0.00( \pm 0.00)$ & $0.00( \pm 0.00)$ & $0.00( \pm 0.00)$ & $0.10( \pm 0.01)$ & $0.00( \pm 0.00)$ \\
\hline Clostridiaceae & $0.00( \pm 0.00)$ & $0.00( \pm 0.00)$ & $0.00( \pm 0.00)$ & $0.00 \pm 0.00)$ & $0.00( \pm 0.00)$ \\
\hline Comamonadaceae & $0.41( \pm 0.51)$ & $2.75( \pm 3.18)$ & $0.06( \pm 0.06)$ & $0.00( \pm 0.00)$ & $0.23( \pm 0.32)$ \\
\hline Coriobacteriaceae & $0.18( \pm 0.00)$ & $0.09( \pm 0.02)$ & $0.08( \pm 0.03)$ & $0.07( \pm 0.02)$ & $0.07( \pm 0.08)$ \\
\hline Corynebacteriaceae & $0.00( \pm 0.00)$ & $0.00( \pm 0.00)$ & $0.02( \pm 0.02)$ & $0.01( \pm 0.02)$ & $2.00( \pm 2.84)$ \\
\hline Coxiellaceae & $0.00( \pm 0.00)$ & $0.00( \pm 0.00)$ & $0.00( \pm 0.00)$ & $0.00( \pm 0.00)$ & $0.08( \pm 0.11)$ \\
\hline Desulfovibrionaceae & $0.15( \pm 0.08)$ & $0.05( \pm 0.04)$ & $0.61( \pm 0.34)$ & $0.36( \pm 0.20)$ & $0.07( \pm 0.08)$ \\
\hline Dietziaceae & $0.00( \pm 0.00)$ & $0.00( \pm 0.00)$ & $0.00( \pm 0.00)$ & $0.00 \pm 0.00)$ & $0.00( \pm 0.00)$ \\
\hline Elusimicrobiaceae & $0.00( \pm 0.00)$ & $0.04( \pm 0.06)$ & $0.03( \pm 0.04)$ & $0.01( \pm 0.01)$ & $0.00( \pm 0.00)$ \\
\hline Enterobacteriaceae & $22.00( \pm 0.92)$ & $15.79( \pm 19.23)$ & $0.03( \pm 0.04)$ & $1.45( \pm 0.31)$ & $4.20( \pm 1.78)$ \\
\hline Enterococcaceae & $0.35( \pm 0.01)$ & $0.25( \pm 0.09)$ & $0.45( \pm 0.19)$ & $0.00( \pm 0.00)$ & $0.02( \pm 0.03)$ \\
\hline Erysipelotrichaceae & $0.08( \pm 0.05)$ & $0.02( \pm 0.00)$ & $0.22( \pm 0.04)$ & $0.03( \pm 0.02)$ & $0.03( \pm 0.04)$ \\
\hline Erythrobacteraceae & $0.00( \pm 0.00)$ & $0.00( \pm 0.00)$ & $0.00( \pm 0.00)$ & $0.00( \pm 0.00)$ & $0.00( \pm 0.00)$ \\
\hline Eubacteriaceae & $0.00( \pm 0.00)$ & $0.00( \pm 0.00)$ & $0.00( \pm 0.00)$ & $0.02( \pm 0.03)$ & $0.01( \pm 0.01)$ \\
\hline Flavobacteriaceae & $0.01( \pm 0.02)$ & $0.19( \pm 0.09)$ & $0.27( \pm 0.15)$ & $0.29( \pm 0.40)$ & $0.29( \pm 0.26)$ \\
\hline Fusobacteriaceae & $0.00( \pm 0.00)$ & $0.00( \pm 0.00)$ & $0.00( \pm 0.00)$ & $0.03( \pm 0.02)$ & $0.00( \pm 0.00)$ \\
\hline Helicobacteraceae & $0.19( \pm 0.17)$ & $0.28( \pm 0.16)$ & $0.10( \pm 0.08)$ & $0.03( \pm 0.04)$ & $0.00( \pm 0.00)$ \\
\hline Lachnospiraceae & $0.54( \pm 0.21)$ & $0.72( \pm 0.23)$ & $0.34( \pm 0.04)$ & $0.82( \pm 0.07)$ & $1.39( \pm 1.50)$ \\
\hline Lactobacillaceae & $1.44( \pm 1.23)$ & $1.18( \pm 0.99)$ & $0.06( \pm 0.09)$ & $0.62( \pm 0.02)$ & $1.07( \pm 1.47)$ \\
\hline Leuconostocaceae & $0.00( \pm 0.00)$ & $0.17( \pm 0.21)$ & $0.01( \pm 0.01)$ & $0.96( \pm 0.97)$ & $1.04( \pm 1.37)$ \\
\hline Methylobacteriaceae & $0.00( \pm 0.00)$ & $0.00( \pm 0.00)$ & $0.05( \pm 0.07)$ & $0.02( \pm 0.03)$ & $0.02( \pm 0.03)$ \\
\hline Methylocystaceae & $0.00( \pm 0.00)$ & $0.00( \pm 0.00)$ & $0.00( \pm 0.00)$ & $0.00( \pm 0.00)$ & $0.00( \pm 0.00)$ \\
\hline Microbacteriaceae & $0.00( \pm 0.00)$ & $0.00( \pm 0.00)$ & $0.00( \pm 0.00)$ & $0.00( \pm 0.00)$ & $0.81( \pm 1.15)$ \\
\hline Moraxellaceae & $0.00( \pm 0.00)$ & $0.35( \pm 0.28)$ & $0.09( \pm 0.06)$ & $0.02( \pm 0.03)$ & $0.15( \pm 0.21)$ \\
\hline Mycobacteriaceae & $0.00( \pm 0.00)$ & $0.00( \pm 0.00)$ & $0.00( \pm 0.00)$ & $0.02( \pm 0.03)$ & $0.00( \pm 0.00)$ \\
\hline Mycoplasmataceae & $0.46( \pm 0.10)$ & $0.27( \pm 0.00)$ & $0.36( \pm 0.13)$ & $0.80( \pm 0.97)$ & $0.26( \pm 0.22)$ \\
\hline Neisseriaceae & $0.08( \pm 0.05)$ & $2.55( \pm 3.61)$ & $0.02( \pm 0.01)$ & $0.19( \pm 0.14)$ & $0.03( \pm 0.04)$ \\
\hline Opitutaceae & $0.07( \pm 0.10)$ & $0.01( \pm 0.01)$ & $0.01( \pm 0.01)$ & $0.02( \pm 0.03)$ & $0.00( \pm 0.00)$ \\
\hline Oxalobacteraceae & $0.00( \pm 0.00)$ & $0.00( \pm 0.00)$ & $0.04( \pm 0.05)$ & $0.00( \pm 0.00)$ & $0.00( \pm 0.00)$ \\
\hline Paenibacillaceae & $0.00( \pm 0.00)$ & $0.00( \pm 0.00)$ & $0.00( \pm 0.00)$ & $0.00( \pm 0.00)$ & $0.08( \pm 0.11)$ \\
\hline Peptococcaceae & $0.02( \pm 0.03)$ & $0.03( \pm 0.04)$ & $0.00( \pm 0.00)$ & $0.00( \pm 0.00)$ & $0.00( \pm 0.00)$ \\
\hline Peptostreptococcaceae & $0.01( \pm 0.02)$ & $0.13( \pm 0.18)$ & $0.00( \pm 0.00)$ & $0.00( \pm 0.00)$ & $0.09( \pm 0.13)$ \\
\hline Planctomycetaceae & $0.14( \pm 0.08)$ & $0.17( \pm 0.03)$ & $0.04( \pm 0.05)$ & $0.09( \pm 0.09)$ & $0.03( \pm 0.04)$ \\
\hline Planococcaceae & $0.00( \pm 0.00)$ & $0.00( \pm 0.00)$ & $0.00( \pm 0.00)$ & $0.00( \pm 0.00)$ & $0.10( \pm 0.15)$ \\
\hline Porphyromonadaceae & $3.10( \pm 0.02)$ & $8.92( \pm 4.02)$ & $4.00( \pm 1.14)$ & $7.01( \pm 1.76)$ & $10.10( \pm 5.08)$ \\
\hline Propionibacteriaceae & $11.21( \pm 7.85)$ & $13.38( \pm 1.56)$ & $6.48( \pm 1.53)$ & $4.65( \pm 0.76)$ & $2.84( \pm 0.85)$ \\
\hline Pseudomonadaceae & $0.00( \pm 0.00)$ & $0.00( \pm 0.00)$ & $0.10( \pm 0.14)$ & $0.00( \pm 0.00)$ & $0.00( \pm 0.00)$ \\
\hline Rhodocyclaceae & $0.90( \pm 0.20)$ & $0.69( \pm 0.56)$ & $3.89( \pm 2.43)$ & $1.75( \pm 1.10)$ & $0.63( \pm 0.61)$ \\
\hline Rhodospirillaceae & $0.25( \pm 0.13)$ & $0.16( \pm 0.01)$ & $0.31( \pm 0.10)$ & $0.49( \pm 0.52)$ & $0.10( \pm 0.09)$ \\
\hline Rikenellaceae & $0.07( \pm 0.00)$ & $0.36( \pm 0.12)$ & $0.28( \pm 0.08)$ & $0.22( \pm 0.02)$ & $0.18( \pm 0.18)$ \\
\hline Ruminococcaceae & $0.51( \pm 0.34)$ & $1.41( \pm 0.48)$ & $0.96( \pm 0.14)$ & $0.84( \pm 0.15)$ & $0.63( \pm 0.15)$ \\
\hline Sanguibacteraceae & $0.00( \pm 0.00)$ & $0.00( \pm 0.00)$ & $0.00( \pm 0.00)$ & $0.00( \pm 0.00)$ & $0.04( \pm 0.05)$ \\
\hline Sphingomonadaceae & $0.00( \pm 0.00)$ & $0.05( \pm 0.07)$ & $0.00( \pm 0.00)$ & $0.03( \pm 0.04)$ & $0.12( \pm 0.17)$ \\
\hline Spirochaetaceae & $11.99( \pm 2.97)$ & $5.41( \pm 3.42)$ & $17.58( \pm 0.75)$ & $5.90( \pm 1.35)$ & $5.42( \pm 5.33)$ \\
\hline Sporolactobacillaceae & $0.00( \pm 0.00)$ & $0.00( \pm 0.00)$ & $0.00( \pm 0.00)$ & $0.06( \pm 0.06)$ & $0.01( \pm 0.02)$ \\
\hline Staphylococcaceae & $0.00( \pm 0.00)$ & $0.00( \pm 0.00)$ & $0.00( \pm 0.00)$ & $0.04( \pm 0.06)$ & $0.00( \pm 0.00)$ \\
\hline Streptococcaceae & $8.49( \pm 0.69)$ & $2.34( \pm 1.25)$ & $5.41( \pm 0.77)$ & $5.45( \pm 0.47)$ & $4.67( \pm 0.31)$ \\
\hline Synergistaceae & $0.44( \pm 0.31)$ & $0.65( \pm 0.30)$ & $0.88( \pm 0.30)$ & $0.84( \pm 0.16)$ & $0.31( \pm 0.21)$ \\
\hline Thermaceae & $0.00( \pm 0.00)$ & $0.00( \pm 0.00)$ & $0.03( \pm 0.04)$ & $0.30( \pm 0.31)$ & $0.00( \pm 0.00)$ \\
\hline Thermoactinomycetaceae & $0.00( \pm 0.00)$ & $0.00( \pm 0.00)$ & $0.00( \pm 0.00)$ & $0.00( \pm 0.00)$ & $0.05( \pm 0.07)$ \\
\hline Veillonellaceae & $0.00( \pm 0.00)$ & $0.05( \pm 0.07)$ & $0.00( \pm 0.00)$ & $0.00( \pm 0.00)$ & $0.04( \pm 0.05)$ \\
\hline Xanthomonadaceae & $0.00( \pm 0.00)$ & $0.02( \pm 0.03)$ & $0.05( \pm 0.07)$ & $0.07( \pm 0.00)$ & $0.21( \pm 0.27)$ \\
\hline The rest & $36.92( \pm 4.73)$ & $41.41( \pm 5.01)$ & $57.07( \pm 5.50)$ & $65.82( \pm 3.47)$ & $61.98( \pm 2.31)$ \\
\hline
\end{tabular}


Supplemental Table 6. Metagenomics analysis of the temperature effect on the symbiotic bacterial population of Reticulitermes speratus KMT001 at the genus level.

\begin{tabular}{|c|c|c|c|c|c|}
\hline \multirow{2}{*}{ Genus } & \multicolumn{5}{|c|}{ Relative content (\%) and standard deviation in parenthesis } \\
\hline & $4^{\circ} \mathrm{C}$ & $10^{\circ} \mathrm{C}$ & $15^{\circ} \mathrm{C}$ & $22^{\circ} \mathrm{C}$ & $26^{\circ} \mathrm{C}$ \\
\hline Achromobacter & $0.00( \pm 0.00)$ & $0.00( \pm 0.00)$ & $0.00( \pm 0.00)$ & $0.00( \pm 0.00)$ & $0.04( \pm 0.06)$ \\
\hline Acidiphilium & $0.00( \pm 0.00)$ & $0.00( \pm 0.00)$ & $0.00( \pm 0.00)$ & $0.04( \pm 0.06)$ & $0.05( \pm 0.07)$ \\
\hline Acidisoma & $0.00( \pm 0.00)$ & $0.00( \pm 0.00)$ & $0.00( \pm 0.00)$ & $0.04( \pm 0.06)$ & $0.00( \pm 0.00)$ \\
\hline Acidovorax & $0.00( \pm 0.00)$ & $0.00( \pm 0.00)$ & $0.00( \pm 0.00)$ & $0.00( \pm 0.00)$ & $0.03( \pm 0.04)$ \\
\hline Acinetobacter & $0.00( \pm 0.00)$ & $0.35( \pm 0.28)$ & $0.09( \pm 0.06)$ & $0.02( \pm 0.03)$ & $0.15( \pm 0.21)$ \\
\hline Actinomyces & $0.00( \pm 0.00)$ & $0.05( \pm 0.07)$ & $0.00( \pm 0.00)$ & $0.00( \pm 0.00)$ & $0.00( \pm 0.00)$ \\
\hline Aestuariimicrobium & $11.17( \pm 7.92)$ & $13.20( \pm 1.34)$ & $6.40( \pm 1.42)$ & $4.33( \pm 0.57)$ & $2.56( \pm 0.85)$ \\
\hline Afipia & $0.00( \pm 0.00)$ & $0.04( \pm 0.06)$ & $0.02( \pm 0.02)$ & $0.08( \pm 0.09)$ & $0.04( \pm 0.05)$ \\
\hline Alicyclobacillus & $0.00( \pm 0.00)$ & $0.00( \pm 0.00)$ & $0.00( \pm 0.00)$ & $0.02( \pm 0.03)$ & $0.00( \pm 0.00)$ \\
\hline Alistipes & $0.02( \pm 0.03)$ & $0.03( \pm 0.04)$ & $0.14( \pm 0.09)$ & $0.05( \pm 0.01)$ & $0.03( \pm 0.01)$ \\
\hline Anaerofustis & $0.00( \pm 0.00)$ & $0.00( \pm 0.00)$ & $0.00( \pm 0.00)$ & $0.02( \pm 0.03)$ & $0.01( \pm 0.01)$ \\
\hline Anaerotruncus & $0.00( \pm 0.00)$ & $0.05( \pm 0.07)$ & $0.00( \pm 0.00)$ & $0.00( \pm 0.00)$ & $0.00( \pm 0.00)$ \\
\hline Bacillus & $0.00( \pm 0.00)$ & $0.00( \pm 0.00)$ & $0.00( \pm 0.00)$ & $0.00( \pm 0.00)$ & $0.19( \pm 0.26)$ \\
\hline Brevinema & $0.20( \pm 0.07)$ & $0.00( \pm 0.00)$ & $0.00( \pm 0.00)$ & $0.00( \pm 0.00)$ & $0.00( \pm 0.00)$ \\
\hline Brevundimonas & $0.00( \pm 0.00)$ & $0.00( \pm 0.00)$ & $0.00( \pm 0.00)$ & $0.05( \pm 0.07)$ & $0.00( \pm 0.00)$ \\
\hline Burkholderia & $0.00( \pm 0.00)$ & $0.00( \pm 0.00)$ & $0.04( \pm 0.06)$ & $0.13( \pm 0.19)$ & $0.06( \pm 0.05)$ \\
\hline Candidatus Captivus & $2.97( \pm 0.22)$ & $1.35( \pm 1.08)$ & $6.33( \pm 1.81)$ & $5.47( \pm 3.24)$ & $6.48( \pm 0.57)$ \\
\hline Candidatus Chloracidobacterium & $0.00( \pm 0.00)$ & $0.00( \pm 0.00)$ & $0.00( \pm 0.00)$ & $0.00( \pm 0.00)$ & $0.00( \pm 0.00)$ \\
\hline Candidatus Hepatincola & $1.51( \pm 0.36)$ & $0.67( \pm 0.51)$ & $3.80( \pm 0.79)$ & $3.35( \pm 1.24)$ & $1.92( \pm 0.55)$ \\
\hline Candidatus Odyssella & $0.00( \pm 0.00)$ & $0.00( \pm 0.00)$ & $0.02( \pm 0.02)$ & $0.06( \pm 0.08)$ & $0.00( \pm 0.00)$ \\
\hline Candidatus Symbiothrix & $1.93( \pm 0.01)$ & $3.52( \pm 0.99)$ & $2.77( \pm 0.71)$ & $3.40( \pm 1.36)$ & $4.41( \pm 3.29)$ \\
\hline Candidatus Tammella & $0.02( \pm 0.03)$ & $0.20( \pm 0.07)$ & $0.13( \pm 0.01)$ & $0.24( \pm 0.09)$ & $0.05( \pm 0.02)$ \\
\hline Chitinophaga & $0.00( \pm 0.00)$ & $0.00( \pm 0.00)$ & $0.00( \pm 0.00)$ & $0.00( \pm 0.00)$ & $0.00( \pm 0.00)$ \\
\hline Chryseobacterium & $0.00( \pm 0.00)$ & $0.03( \pm 0.04)$ & $0.01( \pm 0.01)$ & $0.00( \pm 0.00)$ & $0.00( \pm 0.00)$ \\
\hline Citrobacter & $11.30( \pm 10.19)$ & $0.78( \pm 0.78)$ & $0.01( \pm 0.01)$ & $0.19( \pm 0.23)$ & $1.51( \pm 0.97)$ \\
\hline Cloacibacterium & $0.00( \pm 0.00)$ & $0.00( \pm 0.00)$ & $0.00( \pm 0.00)$ & $0.00( \pm 0.00)$ & $0.16( \pm 0.23)$ \\
\hline Clostridium & $0.00( \pm 0.00)$ & $0.00( \pm 0.00)$ & $0.00( \pm 0.00)$ & $0.00( \pm 0.00)$ & $0.00( \pm 0.00)$ \\
\hline Comamonas & $0.41( \pm 0.51)$ & $2.75( \pm 3.18)$ & $0.06( \pm 0.06)$ & $0.00( \pm 0.00)$ & $0.20( \pm 0.28)$ \\
\hline Corynebacterium & $0.00( \pm 0.00)$ & $0.00( \pm 0.00)$ & $0.02( \pm 0.02)$ & $0.01( \pm 0.02)$ & $2.00( \pm 2.84)$ \\
\hline Cronobacter & $0.33( \pm 0.04)$ & $0.00( \pm 0.00)$ & $0.00( \pm 0.00)$ & $0.00( \pm 0.00)$ & $0.00( \pm 0.00)$ \\
\hline Cupriavidus & $0.00( \pm 0.00)$ & $0.00( \pm 0.00)$ & $0.00( \pm 0.00)$ & $0.00( \pm 0.00)$ & $0.03( \pm 0.03)$ \\
\hline Daeguia & $0.00( \pm 0.00)$ & $0.00( \pm 0.00)$ & $0.00( \pm 0.00)$ & $0.00( \pm 0.00)$ & $0.02( \pm 0.03)$ \\
\hline Delftia & $0.00( \pm 0.00)$ & $0.00( \pm 0.00)$ & $0.00( \pm 0.00)$ & $0.00( \pm 0.00)$ & $0.00( \pm 0.00)$ \\
\hline Desulfovibrio & $0.15( \pm 0.08)$ & $0.05( \pm 0.04)$ & $0.61( \pm 0.34)$ & $0.36( \pm 0.20)$ & $0.07( \pm 0.08)$ \\
\hline Dietzia & $0.00( \pm 0.00)$ & $0.00( \pm 0.00)$ & $0.00( \pm 0.00)$ & $0.00( \pm 0.00)$ & $0.00( \pm 0.00)$ \\
\hline Dyella & $0.00( \pm 0.00)$ & $0.00( \pm 0.00)$ & $0.00( \pm 0.00)$ & $0.00( \pm 0.00)$ & $0.00( \pm 0.00)$ \\
\hline Dysgonomonas & $0.08( \pm 0.01)$ & $2.70( \pm 2.20)$ & $0.34( \pm 0.02)$ & $0.81( \pm 0.18)$ & $2.19( \pm 0.57)$ \\
\hline Edaphobacter & $0.00( \pm 0.00)$ & $0.00( \pm 0.00)$ & $0.00( \pm 0.00)$ & $0.06( \pm 0.08)$ & $0.00( \pm 0.00)$ \\
\hline Elizabethkingia & $0.00( \pm 0.00)$ & $0.06( \pm 0.09)$ & $0.01( \pm 0.01)$ & $0.10( \pm 0.13)$ & $0.08( \pm 0.04)$ \\
\hline Elusimicrobium & $0.00( \pm 0.00)$ & $0.04( \pm 0.06)$ & $0.03( \pm 0.04)$ & $0.01( \pm 0.01)$ & $0.00( \pm 0.00)$ \\
\hline Enterobacter & $0.04( \pm 0.06)$ & $0.00( \pm 0.00)$ & $0.00( \pm 0.00)$ & $0.00( \pm 0.00)$ & $0.00( \pm 0.00)$ \\
\hline Enterococcus & $0.35( \pm 0.01)$ & $0.25( \pm 0.09)$ & $0.45( \pm 0.19)$ & $0.00( \pm 0.00)$ & $0.02( \pm 0.03)$ \\
\hline Ethanoligenens & $0.00( \pm 0.00)$ & $0.00( \pm 0.00)$ & $0.00( \pm 0.00)$ & $0.00( \pm 0.00)$ & $0.02( \pm 0.03)$ \\
\hline Faecalibacterium & $0.00( \pm 0.00)$ & $0.06( \pm 0.09)$ & $0.00( \pm 0.00)$ & $0.00( \pm 0.00)$ & $0.00( \pm 0.00)$ \\
\hline Fusobacterium & $0.00( \pm 0.00)$ & $0.00( \pm 0.00)$ & $0.00( \pm 0.00)$ & $0.03( \pm 0.02)$ & $0.00( \pm 0.00)$ \\
\hline Kiloniella & $0.00( \pm 0.00)$ & $0.08( \pm 0.09)$ & $0.00( \pm 0.00)$ & $0.00( \pm 0.00)$ & $0.00( \pm 0.00)$ \\
\hline Lactobacillus & $1.44( \pm 1.23)$ & $1.18( \pm 0.99)$ & $0.06( \pm 0.09)$ & $0.62( \pm 0.02)$ & $1.07( \pm 1.47)$ \\
\hline
\end{tabular}


Symbiotic Bacterial Flora Changes in Response to Low Temperature in Reticulitermes speratus KMT001

Supplemental Table 6. (Continued)

\begin{tabular}{|c|c|c|c|c|c|}
\hline \multirow{2}{*}{ Genus } & \multicolumn{5}{|c|}{ Relative content (\%) and standard deviation in parenthesis } \\
\hline & $4^{\circ} \mathrm{C}$ & $10^{\circ} \mathrm{C}$ & $15^{\circ} \mathrm{C}$ & $22^{\circ} \mathrm{C}$ & $26^{\circ} \mathrm{C}$ \\
\hline Lactococcus & $6.48( \pm 0.04)$ & $0.73( \pm 0.35)$ & $3.92( \pm 0.65)$ & $1.27( \pm 1.28)$ & $1.29( \pm 1.60)$ \\
\hline Leuconostoc & $0.00( \pm 0.00)$ & $0.17( \pm 0.21)$ & $0.01( \pm 0.01)$ & $0.23( \pm 0.06)$ & $1.04( \pm 1.37)$ \\
\hline Lysinibacillus & $0.00( \pm 0.00)$ & $0.00( \pm 0.00)$ & $0.00( \pm 0.00)$ & $0.00( \pm 0.00)$ & $0.00( \pm 0.00)$ \\
\hline Methylobacterium & $0.00( \pm 0.00)$ & $0.00( \pm 0.00)$ & $0.05( \pm 0.07)$ & $0.02( \pm 0.03)$ & $0.02( \pm 0.03)$ \\
\hline Microbacterium & $0.00( \pm 0.00)$ & $0.00( \pm 0.00)$ & $0.00( \pm 0.00)$ & $0.00( \pm 0.00)$ & $0.37( \pm 0.53)$ \\
\hline Moryella & $0.00( \pm 0.00)$ & $0.00( \pm 0.00)$ & $0.00( \pm 0.00)$ & $0.00( \pm 0.00)$ & $0.04( \pm 0.05)$ \\
\hline Mycobacterium & $0.00( \pm 0.00)$ & $0.00( \pm 0.00)$ & $0.00( \pm 0.00)$ & $0.02( \pm 0.03)$ & $0.00( \pm 0.00)$ \\
\hline Naxibacter & $0.00( \pm 0.00)$ & $0.00( \pm 0.00)$ & $0.00( \pm 0.00)$ & $0.00( \pm 0.00)$ & $0.00( \pm 0.00)$ \\
\hline Novosphingobium & $0.00( \pm 0.00)$ & $0.00( \pm 0.00)$ & $0.00( \pm 0.00)$ & $0.00( \pm 0.00)$ & $0.00( \pm 0.00)$ \\
\hline Odoribacter & $0.15( \pm 0.01)$ & $0.68( \pm 0.26)$ & $0.11( \pm 0.03)$ & $0.10( \pm 0.13)$ & $0.01( \pm 0.01)$ \\
\hline Opitutus & $0.07( \pm 0.10)$ & $0.01( \pm 0.01)$ & $0.01( \pm 0.01)$ & $0.02( \pm 0.03)$ & $0.00( \pm 0.00)$ \\
\hline Paenibacillus & $0.00( \pm 0.00)$ & $0.00( \pm 0.00)$ & $0.00( \pm 0.00)$ & $0.00( \pm 0.00)$ & $0.08( \pm 0.11)$ \\
\hline Paenisporosarcina & $0.00( \pm 0.00)$ & $0.00( \pm 0.00)$ & $0.00( \pm 0.00)$ & $0.00( \pm 0.00)$ & $0.03( \pm 0.05)$ \\
\hline Paludibacter & $0.38( \pm 0.17)$ & $0.24( \pm 0.02)$ & $0.10( \pm 0.05)$ & $0.33( \pm 0.14)$ & $0.35( \pm 0.10)$ \\
\hline Parabacteroides & $0.56( \pm 0.11)$ & $1.66( \pm 0.51)$ & $0.67( \pm 0.39)$ & $2.20( \pm 0.21)$ & $3.05( \pm 1.27)$ \\
\hline Propionibacterium & $0.00( \pm 0.00)$ & $0.17( \pm 0.21)$ & $0.08( \pm 0.12)$ & $0.20( \pm 0.06)$ & $0.23( \pm 0.08)$ \\
\hline Propionicicella & $0.05( \pm 0.06)$ & $0.01( \pm 0.01)$ & $0.00( \pm 0.00)$ & $0.12( \pm 0.12)$ & $0.01( \pm 0.01)$ \\
\hline Propionivibrio & $0.07( \pm 0.09)$ & $0.01( \pm 0.01)$ & $0.03( \pm 0.00)$ & $0.12( \pm 0.08)$ & $0.58( \pm 0.59)$ \\
\hline Pseudoclavibacter & $0.00( \pm 0.00)$ & $0.00( \pm 0.00)$ & $0.00( \pm 0.00)$ & $0.00( \pm 0.00)$ & $0.44( \pm 0.62)$ \\
\hline Pseudomonas & $0.00( \pm 0.00)$ & $0.00( \pm 0.00)$ & $0.10( \pm 0.14)$ & $0.00( \pm 0.00)$ & $0.00( \pm 0.00)$ \\
\hline Rickettsiella & $0.00( \pm 0.00)$ & $0.00( \pm 0.00)$ & $0.00( \pm 0.00)$ & $0.00( \pm 0.00)$ & $0.08( \pm 0.11)$ \\
\hline Riemerella & $0.00( \pm 0.00)$ & $0.00( \pm 0.00)$ & $0.00( \pm 0.00)$ & $0.00( \pm 0.00)$ & $0.03( \pm 0.04)$ \\
\hline Roseburia & $0.00( \pm 0.00)$ & $0.00( \pm 0.00)$ & $0.05( \pm 0.06)$ & $0.05( \pm 0.07)$ & $0.00( \pm 0.00)$ \\
\hline Sanguibacter & $0.00( \pm 0.00)$ & $0.00( \pm 0.00)$ & $0.00( \pm 0.00)$ & $0.00( \pm 0.00)$ & $0.04( \pm 0.05)$ \\
\hline Serratia & $10.27( \pm 9.45)$ & $15.01( \pm 20.00)$ & $0.02( \pm 0.03)$ & $0.94( \pm 0.03)$ & $1.56( \pm 0.15)$ \\
\hline Shimazuella & $0.00( \pm 0.00)$ & $0.00( \pm 0.00)$ & $0.00( \pm 0.00)$ & $0.00( \pm 0.00)$ & $0.05( \pm 0.07)$ \\
\hline Shuttleworthia & $0.00( \pm 0.00)$ & $0.05( \pm 0.07)$ & $0.01( \pm 0.02)$ & $0.27( \pm 0.27)$ & $0.02( \pm 0.03)$ \\
\hline Singulisphaera & $0.00( \pm 0.00)$ & $0.00( \pm 0.00)$ & $0.00( \pm 0.00)$ & $0.08( \pm 0.11)$ & $0.00( \pm 0.00)$ \\
\hline Sphingobium & $0.00( \pm 0.00)$ & $0.00( \pm 0.00)$ & $0.00( \pm 0.00)$ & $0.03( \pm 0.04)$ & $0.12( \pm 0.17)$ \\
\hline Sphingomonas & $0.00( \pm 0.00)$ & $0.05( \pm 0.07)$ & $0.00( \pm 0.00)$ & $0.00( \pm 0.00)$ & $0.00( \pm 0.00)$ \\
\hline Spirochaeta & $0.16( \pm 0.23)$ & $0.12( \pm 0.02)$ & $0.07( \pm 0.08)$ & $0.04( \pm 0.04)$ & $0.03( \pm 0.02)$ \\
\hline Sporolactobacillus & $0.00( \pm 0.00)$ & $0.00( \pm 0.00)$ & $0.00( \pm 0.00)$ & $0.06( \pm 0.06)$ & $0.01( \pm 0.02)$ \\
\hline Staphylococcus & $0.00( \pm 0.00)$ & $0.00( \pm 0.00)$ & $0.00( \pm 0.00)$ & $0.04( \pm 0.06)$ & $0.00( \pm 0.00)$ \\
\hline Stenotrophomonas & $0.00( \pm 0.00)$ & $0.02( \pm 0.03)$ & $0.05( \pm 0.07)$ & $0.07( \pm 0.00)$ & $0.21( \pm 0.27)$ \\
\hline Stenoxybacter & $0.08( \pm 0.05)$ & $2.55( \pm 3.61)$ & $0.02( \pm 0.01)$ & $0.19( \pm 0.14)$ & $0.03( \pm 0.04)$ \\
\hline Streptococcus & $0.00( \pm 0.00)$ & $0.00( \pm 0.00)$ & $0.00( \pm 0.00)$ & $0.00( \pm 0.00)$ & $0.05( \pm 0.06)$ \\
\hline Subdoligranulum & $0.00( \pm 0.00)$ & $0.00( \pm 0.00)$ & $0.00( \pm 0.00)$ & $0.03( \pm 0.04)$ & $0.00( \pm 0.00)$ \\
\hline Tannerella & $0.00( \pm 0.00)$ & $0.12( \pm 0.05)$ & $0.01( \pm 0.01)$ & $0.17( \pm 0.10)$ & $0.10( \pm 0.14)$ \\
\hline Telmatospirillum & $0.00( \pm 0.00)$ & $0.01( \pm 0.01)$ & $0.00( \pm 0.00)$ & $0.00( \pm 0.00)$ & $0.08( \pm 0.06)$ \\
\hline Terriglobus & $0.00( \pm 0.00)$ & $0.00( \pm 0.00)$ & $0.00( \pm 0.00)$ & $0.00( \pm 0.00)$ & $0.00( \pm 0.00)$ \\
\hline Thalassospira & $0.19( \pm 0.21)$ & $0.10( \pm 0.06)$ & $0.22( \pm 0.09)$ & $0.44( \pm 0.44)$ & $0.02( \pm 0.03)$ \\
\hline Thermus & $0.00( \pm 0.00)$ & $0.00( \pm 0.00)$ & $0.03( \pm 0.04)$ & $0.30( \pm 0.31)$ & $0.00( \pm 0.00)$ \\
\hline Treponema & $11.63( \pm 2.67)$ & $5.29( \pm 3.40)$ & $17.45( \pm 0.58)$ & $5.86( \pm 1.38)$ & $5.39( \pm 5.35)$ \\
\hline Weeksella & $0.01( \pm 0.02)$ & $0.09( \pm 0.13)$ & $0.25( \pm 0.15)$ & $0.19( \pm 0.27)$ & $0.02( \pm 0.02)$ \\
\hline Weissella & $0.00( \pm 0.00)$ & $0.00( \pm 0.00)$ & $0.00( \pm 0.00)$ & $0.73( \pm 1.03)$ & $0.00( \pm 0.00)$ \\
\hline Yersinia & $0.06( \pm 0.08)$ & $0.00( \pm 0.00)$ & $0.00( \pm 0.00)$ & $0.00( \pm 0.00)$ & $0.00( \pm 0.00)$ \\
\hline Yokenella & $0.00( \pm 0.00)$ & $0.00( \pm 0.00)$ & $0.00( \pm 0.00)$ & $0.32( \pm 0.10)$ & $0.79( \pm 0.54)$ \\
\hline The rest & $37.93( \pm 5.19)$ & $45.43( \pm 5.58)$ & $55.41( \pm 3.73)$ & $66.08( \pm 10.88)$ & $60.45( \pm 3.26)$ \\
\hline
\end{tabular}

